\title{
Establecimiento in vitro de (Vaccinium consanguineum), un arándano nativo de Costa Rica
}

\section{In vitro establishment of Vaccinium consanguineum, a native blueberry from Costa Rica}

\author{
Vilma Jiménez-Bonilla ${ }^{1}$, Ana Abdelnour-Esquivel ${ }^{2}$
}

Fecha de recepción: 2 de julio del 2015

Fecha de aprobación: 26 de octubre del 2015

Jiménez-Bonilla, V; Abdelnour-Esquivel, A. Establecimiento in vitro de (Vaccinium consanguineum), un arándano nativo de Costa Rica. Tecnología en Marcha. Vol. 29, № 2, Abril-Junio 2016. Pág 77-84.

1 Centro de Investigación en Biotecnología, Escuela de Biología, Instituto Tecnológico de Costa Rica. Correo electrónico: vijimenez@itcr.ac.cr

2 Centro de Investigación en Biotecnología, Escuela de Biología. Instituto Tecnológico de Costa Rica. Correo electrónico: aabdelnour@itcr.ac.cr 


\title{
Palabras clave
}

Arándano; antioxidantes; hipoclorito de sodio y calcio y $\mathrm{HgCl}_{2}$.

\section{Resumen}

En Costa Rica, el arándano es una de las especies silvestres cuya domesticación ha despertado gran interés, ya que es horticulturalmente promisorio. Por esta razón se incluyó como línea de investigación en el área de cultivos no tradicionales del Programa Nacional de Fruticultura (Ing. Alberto Montero, Gerente del Programa Nacional de Frutas No Tradicionales del Ministerio de Agricultura y Ganadería, Noviembre 2014 San José, Costa Rica, comunicación personal). El objetivo de esta investigación fue desarrollar un protocolo de establecimiento in vitro de esta especie, como parte del proyecto Arándano: Una opción para la diversificación de la agricultura de las zonas altas del país, con el fin de contar con material aséptico que permita continuar con el desarrollo de las siguientes etapas del proceso de micropropagación. Para el establecimiento in vitro se utilizaron miniestacas tomadas directamente del campo, con 2 y 3 nudos, se lavaron con abundante agua y jabón por 30 minutos, posteriormente se desinfectaron con varias soluciones como hipoclorito de sodio y calcio y cloruro de mercurio $\left(\mathrm{HgCl}_{2}\right)$, en varias concentraciones. La solución que permitió los mayores porcentajes de estacas establecidas asépticamente fue $\mathrm{HgCl}_{2}$ al $0,2 \%$ durante 5 minutos. El medio utilizado fue un WPM con $1 \mathrm{~g} / \mathrm{l}$ de carbón activado. Las estacas establecidas asépticamente se utilizaran para evaluar el efecto de varios reguladores del crecimiento en la brotación de las yemas.

\section{Keywords}

Blueberry; antioxidants; sodium and calcium choride; $\mathrm{HgCl}_{2}$.

\begin{abstract}
In Costa Rica, blueberry is one of the wild species whose domestication has aroused great interest, since it is horticulturally promising. For this reason it was included as a line of research in the area of non-traditional fruit crops in the Fruit Growing National Program (Eng. Alberto Montero, national program manager of the non-traditional fruits in the Ministry of Agriculture and Livestock, November 2014, San Jose, Costa Rica, personal communication). The objective of this research was to develop a protocol for in vitro establishment of this species, as part of the blueberry project: an option for the diversification of agriculture in the Highlands of the country, in order to count with aseptic material that allows to continue with the development of the following stages of micropropagation process. For the in vitro establishment, micro cuttings with 2 and 3 knots were taken directly from the field, washed with detergent and water for 30 minutes, then were disinfected with several solutions such as sodium and calcium hypochlorite and Mercury chloride $\left(\mathrm{HgCl}_{2}\right)$, in various concentrations. The solution that allowed the highest percentages of micro cuttings established aseptically was $\mathrm{HgCl} 20.2 \%$ for 5 minutes. The medium used was a WPM with $1 \mathrm{~g} / \mathrm{l}$ of activated charcoal. Micro cuttings established aseptically will be utilized to assess the effect of multiple regulators of growth in the sprouting of buds.
\end{abstract}

\section{Introducción}

El arándano es un arbusto de la familia de las ericáceas, género Vaccinium. Sus frutos son bayas de color oscuro, azuladas o rojizas, ricas en antocianos y minerales. Sus cualidades nutricionales y antioxidantes hacen del arándano un fruto de alto valor medicinal y nutricional. 
Estudios recientes (Jiménez-Bonilla \& Abdelnour-Esquivel, 2013) confirmaron el valor nutricional del arándano nativo de Costa Rica. Se compararon los índices de actividad antioxidante mostrados para arándanos comerciales (94 y $92 \mu \mathrm{M}$ de Trolox equivalente/g muestra fresca) (Inkanatural, 2008), los cuales son menores a los arrojados por los análisis de los arándanos silvestres en el estudio (entre 550 y $650 \mu \mathrm{M}$ ). Además, los valores reportados para ciruela (73), mora (53), frambuesa (48), manzana (43) y naranja (18), entre otros (Inkanatural, 2008), también muestran valores muy inferiores a los determinados en los materiales silvestres analizados.

Desde hace algunos años, los principales supermercados de Costa Rica importan esta fruta procesada en diferentes presentaciones (jugos, mermeladas, toppings, pasteles y otros) y más recientemente como fruta congelada. PROCOMER (2012) señala que las frutas de Vaccinium se importan desde Chile, Colombia, México y Estados Unidos y que las divisas invertidas para ello han ido en aumento en los últimos años, pasando de US\$48.000 en 2007 a US\$215.100 en 2013, lo que muestra el incremento en el consumo nacional de estas frutas. Sin embargo, por su alto precio en el mercado nacional, es probable que su consumo esté limitado a un sector selecto de la población. Con base en estos resultados, así como en la información sobre el aumento en el consumo de arándano y las crecientes divisas que invierte el país en la importación de productos a base de esta fruta, se evidenció la necesidad de incentivar y apoyar las iniciativas de domesticar estas plantas para introducirlas en la producción comercial.

La micropropagación es una de las técnicas que permiten lograr plantas con características genéticas similares a la que les dio origen. Una de sus etapas es el establecimiento in vitro, que está limitado por la ocurrencia de contaminantes fúngicos y bacteriológicos que colonizan el explante y el medio de cultivo, ocasionando su muerte y oxidación. Este constituye uno de los problemas más serios y frecuentes, tanto al inicio del proceso como durante el mantenimiento de un tejido cultivado in vitro y se considera la mayor limitante del desarrollo de un protocolo de micropropagación. Por lo anterior, se desarrolló este estudio de establecimiento in vitro de miniestacas tomadas de material que crecía en campo, con el fin de sentar las bases del protocolo de micropropagación de esta especie.

\section{Materiales y métodos}

\section{Recolección}

Se seleccionó el material de arándano identificado previamente como "Las Torres 2", localizado en el Cerro de la Muerte, que mostró, durante estudios previos, tener las características deseables para la producción comercial (color, tamaño y sabor) y los mayores contenidos de antioxidantes de los materiales evaluados (Cuadro 1). Se realizaron 16 giras de recolección por año. Se recolectaron tallos jóvenes poco lignificados, que se envolvieron en papel toalla humedecido con agua y se colocaron en una hielera para su traslado al laboratorio de cultivo de tejidos del Centro de Investigaciones en Biotecnología (CIB), del Instituto Tecnológico de Costa Rica.

\section{Establecimiento in vitro}

Los tallos recolectados se seccionaron en estacas que contenían de 2 a 3 nudos y se eliminaron las hojas. Posteriormente, se lavaron con agua y jabón quirúrgico en forma individual con ayuda de un cepillo suave, se enjuagaron tres veces con abundante agua y se sometieron a diferentes tratamientos con desinfectantes (Cuadro 2). 
Cuadro 2. Tratamientos desinfectantes, concentraciones y tiempos de incubación de las miniestacas de arándano (Vaccinium consanguineum)

\begin{tabular}{|c|c|c|c|}
\hline Tratamiento & Desinfectante & Concentración & Tiempo (min) \\
\hline \multirow{5}{*}{1} & Alcohol & $70 \%$ & 5 \\
\hline & Benomyl & & \\
\hline & Agrimicin & & \\
\hline & Ferbán & $6 \mathrm{~g} / \mathrm{L}$ & 60, en agitación \\
\hline & $\begin{array}{c}\text { Hipoclorito de calcio } \\
(68 \% \text { i.a. })\end{array}$ & $8 \%$ & 10, en agitación \\
\hline \multirow{5}{*}{2} & Alcohol & $70 \%$ & 5 \\
\hline & Benomyl & & \\
\hline & Agrimicin & & 00 \\
\hline & Ferbán & $6 \mathrm{~g} / \mathrm{L}$ & 60, en agitación \\
\hline & Hipoclorito de calcio & $10 \%$ & 10, en agitación \\
\hline \multirow{5}{*}{3} & Alcohol & $70 \%$ & 5 \\
\hline & Benomyl & & \\
\hline & Agrimicin & $\sigma_{0}$ & 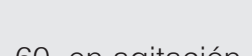 \\
\hline & Ferbán & $6 \mathrm{~g} / \mathrm{L}$ & 60, en agıtacion \\
\hline & Hipoclorito de sodio & $1,5 \%$ & 10, en agitación \\
\hline \multirow{5}{*}{4} & Alcohol & $70 \%$ & 5 \\
\hline & Benomyl & & \\
\hline & Agrimicin & & \\
\hline & Ferbán & $6 \mathrm{~g} / \mathrm{L}$ & 60, en agitación \\
\hline & Hipoclorito de sodio & $1,5 \%$ & 20, en agitación \\
\hline \multirow{5}{*}{5} & Alcohol & $70 \%$ & 5 \\
\hline & Benomyl & & \\
\hline & Agrimicin & & \\
\hline & Ferbán & $6 \mathrm{~g} / \mathrm{L}$ & 60, en agitación \\
\hline & Hipoclorito de sodio & $3 \%$ & 10, en agitación \\
\hline \multirow{5}{*}{6} & Alcohol & $70 \%$ & 5 \\
\hline & Benomyl & & \\
\hline & Agrimicin & & \\
\hline & Ferbán & $6 \mathrm{~g} / \mathrm{L}$ & 60, en agitación \\
\hline & Hipoclorito de sodio & $1,5 \%$ & 15, en agitación \\
\hline 7 & $\begin{array}{c}\text { Cloruro de mercurio } \\
\qquad\left(\mathrm{HgCl}_{2}\right)\end{array}$ & $0,175 \%$ & 5 \\
\hline 8 & $\begin{array}{c}\text { Cloruro de mercurio } \\
\left(\mathrm{HgCl}_{2}\right)\end{array}$ & $0,20 \%$ & 5 \\
\hline 9 & $\begin{array}{l}\text { Cloruro de mercurio } \\
\qquad\left(\mathrm{HgCl}_{2}\right)\end{array}$ & $0,175 \%$ & 6 \\
\hline
\end{tabular}


Después de cada tratamiento de desinfección se realizaron al menos tres enjuagues con agua destilada estéril en la cámara de transferencia de flujo laminar y durante la siembra en los envases de cultivo el material vegetal se mantuvo en una solución antioxidante de $500 \mathrm{mg} / \mathrm{l}$ de ácido cítrico y $250 \mathrm{~m} / \mathrm{l}$ de ácido ascórbico (previamente esterilizados). Se sembró un explante por envase de cultivo conteniendo $20 \mathrm{ml}$ del medio descrito por Murashige y Skoog (MS) (1962) en ausencia de reguladores de crecimiento, con un $\mathrm{pH}$ ajustado a 5,7.

Se colocaron los explantes en el cuarto de crecimiento, con una temperatura ambiente de $21^{\circ} \mathrm{C}$ a $22{ }^{\circ} \mathrm{C}$ en la oscuridad durante ocho días. Posteriormente, se mantuvieron en el mismo cuarto de crecimiento pero en luz directa (2000 Lux), con un fotoperiodo de 16 horas luz. También se evaluó el efecto de temperaturas mayores y menores sobre la brotación de las yemas, colocando los explantes en un cuarto de crecimiento con una temperatura de $27^{\circ} \mathrm{C}$ y dándoles un pretratamiento de frío a $5^{\circ} \mathrm{C}$ en la refrigeradora.

Cada unidad experimental consistió de un explante por envase de cultivo con 50 repeticiones y cada experimento se repitió al menos dos veces. La evaluación se realizó semanalmente durante ocho semanas, tomando en cuenta el número de explantes establecidos de manera aséptica, explantes contaminados (hongos-bacterias), oxidados y muertos.

\section{Resultados}

\section{Establecimiento in vitro}

El análisis de varianza (ANOVA) evidenció diferencias significativas entre los tratamientos. Para la desinfección, los tratamientos 1, 2, 3 y 4 resultaron estadísticamente iguales entre sí; los tratamientos 7 y 8 estadísticamente similares entre sí. Sin embargo, los tratamientos 5 y 6 presentaron diferencias significativas con respecto a los primeros mencionados; los tratamientos 7 y 8 guardan similitud entre ellos y con el tratamiento 9. El tratamiento que permitió los menores porcentajes de oxidación de explantes fue el No. 9, pero no presentó diferencia estadística significativa con respecto al tratamiento 8.

El uso de hipoclorito de calcio en las concentraciones y tiempos de incubación evaluados permitió altos porcentajes de contaminación de miniestacas, lo mismo que los tratamientos que incluyeron la incubación en hipoclorito de sodio al 1,5\% i.a. durante 10 y 20 min (tratamientos 1, 2, 3 y 4) (entre $80 \%$ y 90\% de contaminación). Por otra parte, al aumentar la concentración de hipoclorito de sodio al 3\% y realizar la incubación por 10 y 15 min, los porcentajes de contaminación disminuyeron significativamente (55\% y 50\% de miniestacas contaminadas, respectivamente). El uso de cloruro de mercurio permitió la menor contaminación y el mayor porcentaje de explantes establecidos asépticamente. De acuerdo con el análisis estadístico, el mejor tratamiento consistió en la incubación en $0,2 \%$ de cloruro de mercurio durante 6 min (28\% de contaminación) (figura 1A).

También se evaluó la oxidación que presentaron las miniestacas de arándano con base en los tratamientos utilizados para la desinfección, después de ocho semanas de cultivo. La prueba de Fisher evidenció diferencias significativas entre los tratamientos. Los tratamientos 1 y 5 no presentaron diferencia estadísticamente significativa con respecto a los demás, los tratamientos 2, 3 y 4 no presentaron diferencia entre sí, los tratamientos 6, 8 y 9 tampoco mostraron diferencia significativa entre sí. Los menores porcentajes de miniestacas oxidadas se observaron en los tratamientos 7,8 y 9 (40\% de oxidación) (figura 1B). 

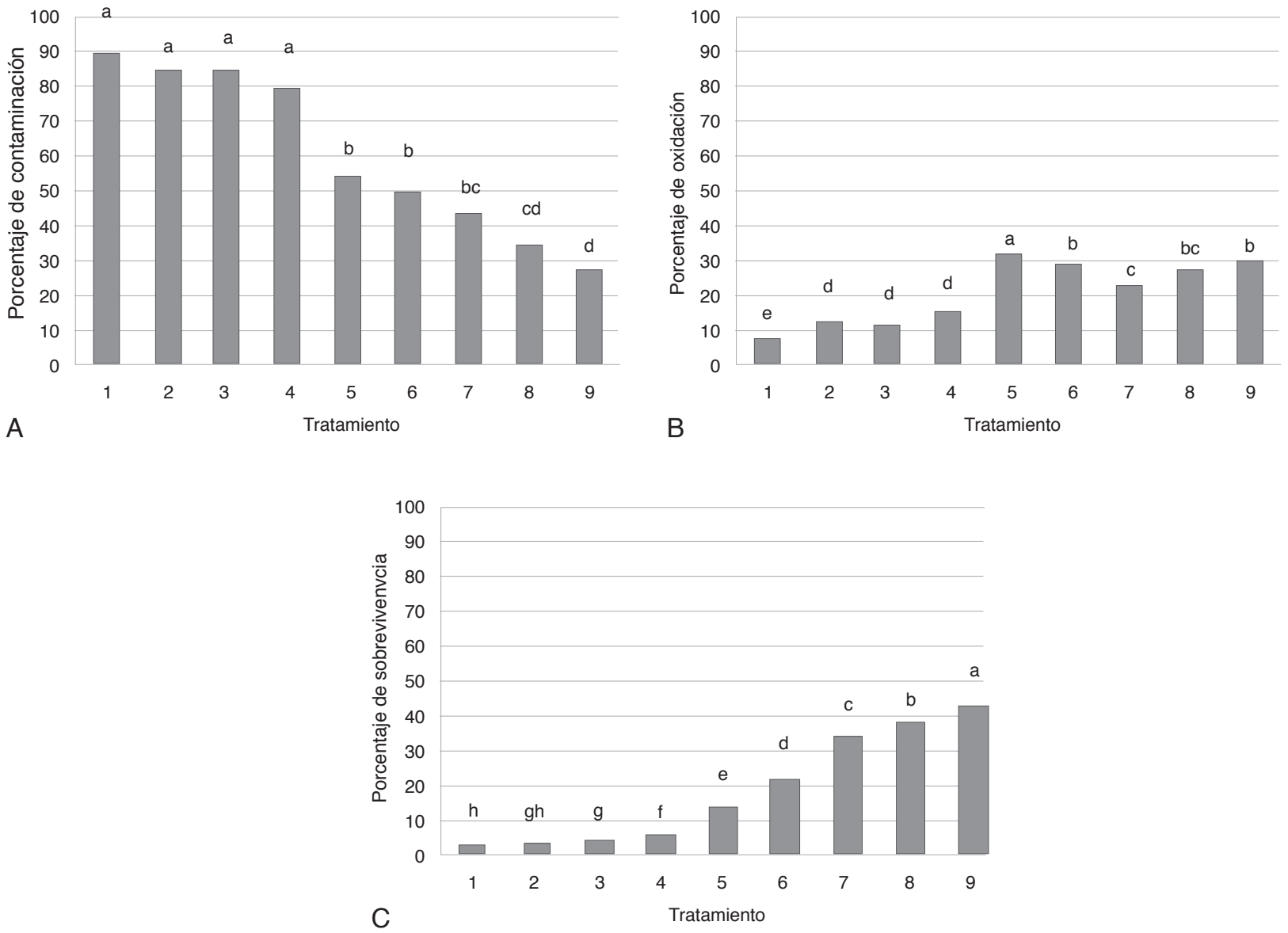

Figura 1. Contaminación (A), oxidación (B) y supervivencia $(C)$ de miniestacas de arándano (Vaccinium consanguineum) según el tratamiento de desinfección, después de ocho semanas de cultivo.

En cuanto a la supervivencia de las miniestacas después de los tratamientos de desinfección (figura 1C), los mayores porcentajes de explantes se observaron en los tratamientos 7, 8 y 9 (33,6\%, 37,7\% y 42,5\%, respectivamente), aunque son estadísticamente diferentes entre sí. El tratamiento 9 permitió el mayor porcentaje de miniestacas sobrevivientes, luego de eliminar los explantes contaminados y oxidados.

\section{Discusión}

El material vegetativo obtenido directamente del campo posee en su superficie una abundante microflora que debe ser eliminada por medio de procedimientos de desinfección para cumplir con el establecimiento aséptico, el cual es la fase número uno y fundamental en cualquier metodología de propagación (George, Hall \& De Klerk, 2008). En los primeros seis tratamientos de desinfección se combinó el uso de desinfectantes como biocidas de acción superficial (alcohol, hipoclorito de calcio y sodio) con dos sistémicos de amplio espectro, benomyl (Benlate $\AA$ ) y estreptomicina y terramicina (Agri-mycin $\AA$ ), tras evaluar concentraciones y tiempos de exposición que no ocasionaran daños a los tejidos. Los resultados mostraron no ser los más efectivos para la descontaminación del material (figura 1), por lo que se debe tomar en cuenta que, al ser material del campo, la probabilidad de contaminación por hongos y bacterias es grande, ya que el grado de contaminación está determinado por las condiciones climáticas 
de la región; es más difícil obtener explantes limpios de plantas del trópico húmedo que de las regiones frías o secas (Rathore et al., 2007).

Dado lo anterior, se recurrió al uso de cloruro de mercurio, el cual se utiliza para la eliminación exófita de microorganismos y se menciona que tiene gran acción bacteriostática y fungicida en concentraciones mayores a 0,004\% (Niubóu et al., 2004). En esta investigación se determinó que, con el empleo de cloruro de mercurio al 0,02\% durante 5 y 6 min, se obtuvieron bajos porcentajes de contaminación, lo que resultó muy efectivo. Tratamientos similares fueron efectivos para desinfectar propágulos de caña (Niubó et al., 2004), teca (Abdelnour \& Muñoz, 2005) y amarillón (Mendez-Álvarez \& Abdelnour-Esquivel, 2014), entre otros. Durante la desinfección, los explantes sufren, en mayor o menor medida, situaciones de estrés, desecación y daños mecánicos que estimulan el metabolismo de los compuestos fenólicos (López, 2004) que son tóxicos para los tejidos vegetales, provocando cese del crecimiento, oscurecimiento de los tejidos vegetales, exudados que oscurecen el medio de cultivo y en algunos casos la muerte del explante (Cáceres, 2006).

En este estudio, la oxidación fue una variable de consideración que constituyó también uno de los problemas más serios y frecuentes, provocando la muerte del material, evidenciándose en los tratamientos de desinfección utilizando desinfectantes como alcohol e hipoclorito de calcio y sodio, que aumentaron los porcentajes de oxidación. Azofeifa (2009) sugiere que los problemas de oxidación podrían reducirse con el uso de un medio líquido con carbón activado. En este estudio, los enjuagues con antioxidantes (ácido ascórbico y cítrico) y la adición de carbón activado al medio de cultivo (500mg/l) fueron efectivos para disminuir la oxidación. Sin embargo, el uso de cloruro de mercurio en bajas concentraciones y periodos cortos de contacto con el material mostró ser más efectivo, tanto para la desinfección como para la disminución de las miniestacas oxidadas, con lo que se logró disponer de material aséptico para iniciar la siguiente fase de micropropagación.

\section{Agradecimientos}

Las investigadoras agradecen el apoyo financiero de la Vicerrectoría de Investigación y Extensión del Instituto Tecnológico de Costa Rica.

\section{Bibliografía}

Abdelnour, A. \& Muñoz, A. (1999). Rescate, establecimiento y conservación de orquídeas en vías de extinción. Tecnología en Marcha, 13, 24-30.

Azofeifa. A. (2009). Problemas de oxidación y oscurecimiento en explantes cultivados in vitro. Agronomía Costarricense, 20(1), 153-175.

Cáceres, K. (2006). Propagación in vitro de portainjertos de cerezo (Prunus cerasus). Pontificia Universidad Católica de Valparaíso (PUCV).

George, E., Hall, M.A. \& De Klerk, G. (2008). Plant Propagation by Tissue Culture. Vol. 1. 3 ed. Springer.

Inkanatural. (2008). Acai: Fruto amazónico para dieta. Disponible en www.inkanatural.com/es/arti.asp

Jiménez-Bonilla, V. \& Abdelnour-Esquivel, A. (2013). Identificación y valor nutricional de algunos materiales nativos de arándano (Vaccinium spp). Tecnología en Marcha, 26(2), 38.

López, E. (2004). Reacciones de hipersensibilidad en plantas cultivadas in vitro. Estación Experimental de la Mayorca CSI. Disponible en <http:// www. Ciencias .uma.es/publicaciones/ ENCUENTROS 26/reacciones .html>

Méndez-Álvarez, D. \& Abdelnour-Esquivel, A. (2014). Méndez-Álvarez, D. Establecimiento in vitro de Terminalia amazonia (Gmel.) Excell. Revista Forestal Mesoamericana Kurú (Costa Rica) Volumen 11(27): 7-21 
Murashige T. \& Skoog F. (1962). A revised medium for rapid growth and bioassays with tobacco tissue culture. Physiol. Plant, 15, 473-497.

Niubó, E., Díaz, P., Oliva, O., Portieles, R., Díaz, A., Ancheta, O., Rodríguez, S., Soto, A. \& Cecilia, S. (2004). Metodología para la obtención in vitro de plantas y tejidos de la caña de azúcar libre de contaminantes exófilos endófitos. Ciencias Biológicas, 35(3), 155-161. Disponible en http://www.redalyc.org/articulo.oa?id=181225915004

PROCOMER. (2012). Portal estadístico de comercio exterior. Costa Rica. Disponible en http://servicios. procomer. go.cr/estadisticas/inicio.aspx

Rathore, J.S., Rathore, M.S., Singh, M., Singh, R.P. \& Shekhawat, N.S. (2007). Micropropagation of mature tree of Citrus limon. Disponible en http://nopr.niscair.res.in/bitstream/123456789/5026/1/IJBT\%206\%282\%29\%20239244.pd 